\title{
Mechanics Parameter Optimization and Evaluation of Curtain Grouting Material in Deep, Water-Rich Karst Tunnels
}

\author{
Hai Shi, ${ }^{1,2}$ Mingzhou Bai, ${ }^{1,3}$ and Shaochuan Xing ${ }^{1}$ \\ ${ }^{1}$ School of Civil Engineering, Beijing Jiaotong University, Beijing, China \\ ${ }^{2}$ Key Laboratory of Track Engineering, Beijing, China \\ ${ }^{3}$ Beijing Engineering and Technology Research Center of Rail Transit Line Safety and Disaster Prevention, Beijing, China \\ Correspondence should be addressed to Hai Shi; 516519566@qq.com
}

Received 11 January 2017; Revised 16 June 2017; Accepted 19 June 2017; Published 28 August 2017

Academic Editor: Antonio Riveiro

Copyright (C) 2017 Hai Shi et al. This is an open access article distributed under the Creative Commons Attribution License, which permits unrestricted use, distribution, and reproduction in any medium, provided the original work is properly cited.

\begin{abstract}
Mud and water often gush suddenly during the construction process of deep buried karst tunnels, which may cause serious accidents and result in major economic losses. Accordingly, for tunnels buried in deep rich water districts, discovering how to effectively control water gushing and ensure the stability of surrounding rock has great influence on the safety of engineering construction. The case study in this paper simulates the water-rich section of Dou-mo tunnel from Shanghai to Kunming of China. Numerical analysis was used to simulate the construction of the curtain grouting section and to evaluate the effects of the various curtain grouting parameters. The optimal grouting parameters were selected and then evaluated by applying them to the grouting method. The results show that (1) the grouting effect is the most notable one when the thickness of the grouting circle is outside the $4 \mathrm{~m}$ range of the tunnel contour. (2) In the same circle, the grouting quantity of the same ring is presented as a wave form. Therefore the number of the same ring grouting holes should reduce and increase the distance between the adjacent grouting holes appropriately to reduce the number of grouting holes and speed up the grouting progress.
\end{abstract}

\section{Introduction}

With the rapid development of high-speed railways, more and more deep, water-rich tunnels are being built in the karst area of Southwest China. During the construction process of these tunnels, problems such as water gushing and mud often restrict the smooth progress and safety of engineering. The presence of gushing water and mud in the tunnel increases the difficulty of the construction and often delays the project, which may also result in huge economic losses and major casualties [1-4]. During tunnel construction, long-time groundwater discharge often severely degrades the ground ecological environment causing the surface to crack and ultimately collapse. Therefore, key problems in the construction of deep water tunnel include discovering how to control water gushing and mud as well as ensuring the stability of the surrounding rock [5-7].

Grouting technology can reinforce fractured rock mass and control karst water hazards. Preconfigured osmotic slurry is usually injected into aquifer through a static pressure grouting method or high pressure jet grouting method according to the hydrogeological conditions of the tunnel and characteristics of tunnel water gushing and mud. This process forms a water channel of a certain strength using the surrounding rocks to ensure its stability and control water gushing [8-10]. However, the current understanding of this method is mostly based on the research of grouting materials and grouting techniques. Relatively few studies have considered grouting parameter optimization or grouting performance evaluation research. Grouting parameters determined at large levels depend on engineering experience, where the grouting effect and economic investment are often difficult to control [11-14].

In recognizing the absence of this research, this paper examines the building of the Dou-mo tunnel in the Shanghai to Kunming high-speed railway as a study case. Curtain grouting based on cave patterns and other characteristics revealed by drilling and advance geological prediction is 
TABLE 1: Physical and mechanical parameters of the surrounding rock.

\begin{tabular}{lccccc}
\hline $\begin{array}{l}\text { Density } \\
\left(\mathrm{kg} / \mathrm{m}^{3}\right)\end{array}$ & $\begin{array}{c}\text { Modulus of } \\
\text { elasticity } \\
(\mathrm{Gpa})\end{array}$ & $\begin{array}{c}\text { Poisson's } \\
\text { ratio }(\mathrm{v})\end{array}$ & Area & Friction angle & $\begin{array}{c}\text { Cohesive force } \\
(\mathrm{Mpa})\end{array}$ \\
\hline 2500 & 6 & 0.25 & $100 * 100$ & 50 & $\begin{array}{c}\text { Permeability } \\
\text { coefficient } \\
(\mathrm{m} / \mathrm{h})\end{array}$ \\
\hline
\end{tabular}

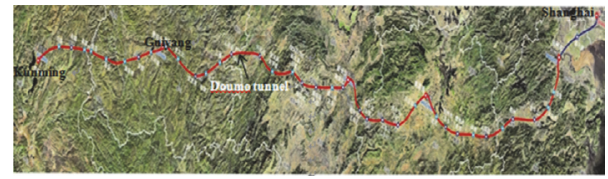

FIgURE 1: Tunnel location diagram.

used to control water gushing and excavation face stability. Using these observations, we determine reasonable optimized grouting parameters and then apply them in the grouting scheme to evaluate its effect. The results of our study provide reference for the construction of this kind of deep buried, high pressure, and water-rich tunnel.

\section{Project Overview}

The Dou-mo tunnel is located in the Guizhou section of the Shanghai to Kunming high-speed railway, from the Anshun west station to the Guanling station interval. It is a double-lane tunnel passenger dedicated line with a design speed of $350 \mathrm{~km} / \mathrm{h}$. The tunnel import and export mileage is D1K841+144 and D1K843+220, respectively. The length of the tunnel is $2076 \mathrm{~m}$. The rock strata where the tunnel goes through the surface include a lower Permian series of Maokou group (plm) limestone; the Permian system of Longtan formation (p2l) mudstone and shale intercalated with sandstone, limestone, and coal seams; the Permian system Changxing Dalong formation $(\mathrm{P} 2 \mathrm{c}+\mathrm{d})$ mudstone, sandstone, and marl rock clip coal line; the lower Triassic Yelang EC group (T1y) clay rock, siltstone and limestone, and argillaceous limestone; the lower Triassic system Yongning group (T1yn1) limestone, dolomitic limestone, mudstone, and marl; and the Triassic system Yongning group second segment (Tlyn2) dolomite, argillaceous dolomite, and argillaceous dolomite folder marl. The tunnel site belongs to the tectonic erosion of the low mountains. The maximum depth of the vault is about $250 \mathrm{~m}$; the tunnel location diagram is shown in Figure 1 [15].

The upper stage working face of the tunnel exit is constructed to D1K842+697. The formation lithology is gray, thick-bedded argillaceous limestone belonging to the lower Triassic Yelang group. The attitude of bed is N35 W/48 S. There is a 67-degree angle between the strata trend and tunnel. The rock quality is hard with good integrity. A karst cave developed in a great depression 30 142 meters from the right side of D1K842+200 +350. There is a hollow on the left side of the D1K842+736 +765. From 3 to 30 meters in front of working face there is a rich, water-soluble cavity containing serious mud.
The distribution form and size of the filling cavity at tunnel exit D1K842+697 can be roughly inferred according to the details of the drilling site and advance geological forecast. The schematic diagram of the cavity is shown in Figures 2 and 3.

The main difficulties in the treatment of the D1K842+697 filling cavity include the great slurry pressure and large discharge amount during the initial stage, large predrainage workload, and a dangerous field operation. The filling solution cavity distribution is wider than the tunnel contour range. The surrounding rock mass strength is low and prone to landslides as well as water mud inrush. The difficulty of excavation support is relatively high. After the initial release of dissolved water, large areas of pores are formed, which, if not properly handled, will affect the safety of the tunnel after operation [16].

Considering the difficulties and potential risks listed above through scheme comparison and selection, we chose curtain grouting as the reinforcement measure to deal with D1K842+697 tunnel face water-rich solution cavity. Step 3 is the excavation method that uses temporary bracing and supporting in accordance with the Dou-mu V-grade surrounding rock section of tunnel timbering parameter support.

\section{Model Analysis of the Curtain Grouting in the Water-Rich Filling Area}

The numerical simulation based on the geological conditions is carried out to study grouting construction of the specific grouting section. Then, the influence of the grouting section excavation and grouting parameters on curtain grouting are determined. In light of this information, we designed the simulation with a variety of operating conditions, which are mainly used to study the relative relationship between the seepage field, the displacement field, and the plastic zone in the surrounding areas of the tunnel, using different grouting parameters.

3.1. Model Establishment. We used ABAQUS to establish a three-dimensional model, which is $100 \mathrm{~m} * 100 \mathrm{~m} * 50 \mathrm{~m}$, where 100 is the maximum height. The surface is simulated by the actual surface conditions of the field. The grid cell is linear and consists of the tetrahedral type C3D4P. The constitutive model is an ideal elastic-plastic Mohr-Coulomb model. The physical and mechanical parameters of the materials are shown in Table 1, which are in accordance with the geological geophysical prospecting data. The model is shown in Figures 4,5 , and 6 .

The boundary conditions for the calculated model are as follows: the displacement boundary adopts the displacement 


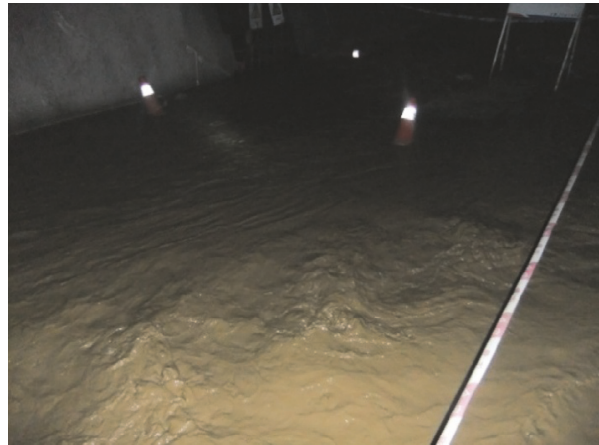

(a) Tunnel burst mud

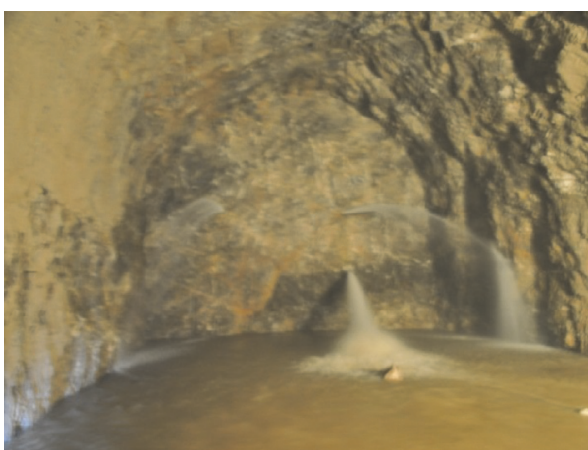

(b) Tunnel water gushing

Figure 2: Research section tunnel site water and mud inrush.

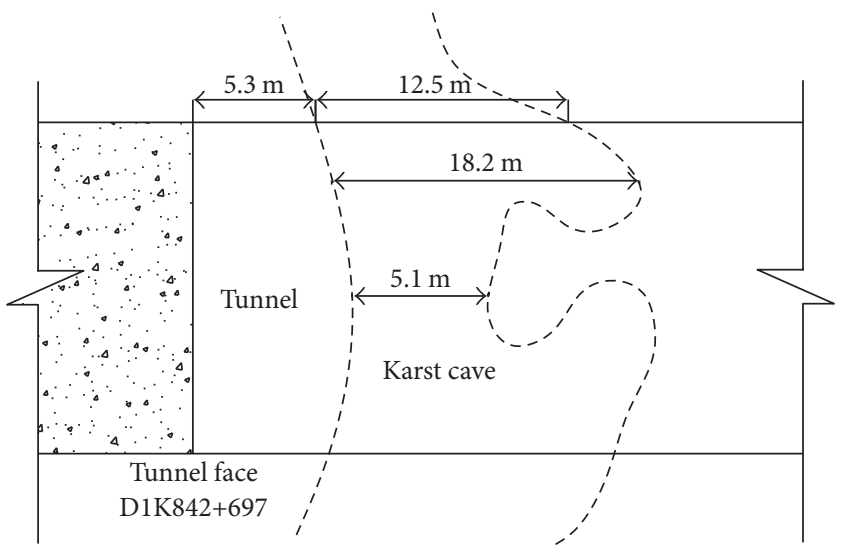

(a) Tunnel exit cave plane

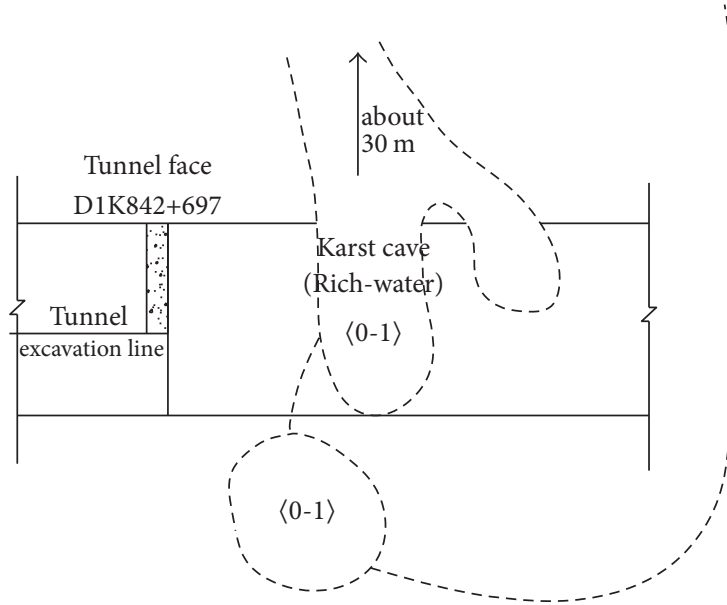

(b) Longitudinal section of exit of tunnel left line

FIgURE 3: Schematic diagram of cavity at the tunnel exit.

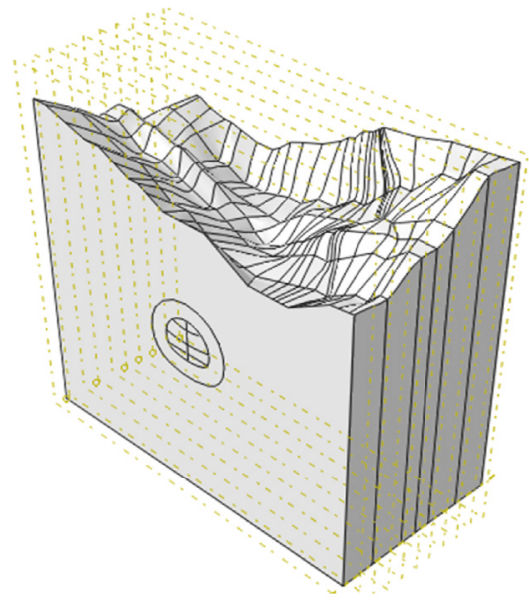

FIGURE 4: Outer contour of curtain grouting model.

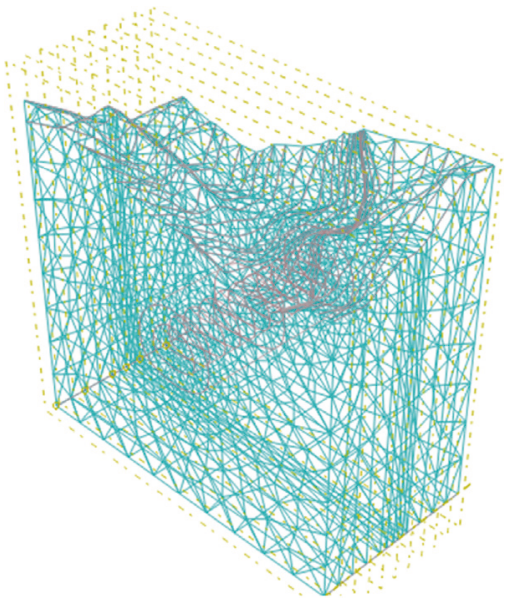

FIGURE 5: Mesh division. constraint; that is, restrict the $X$-direction displacement in the left and right boundaries, restrict the $Y$-direction displacement on the bottom boundary; and leave the top surface free. A water permeable boundary is set around the seepage boundary and its bottom, which allows the surrounding karst water and fractured water to carry the water supply to the 


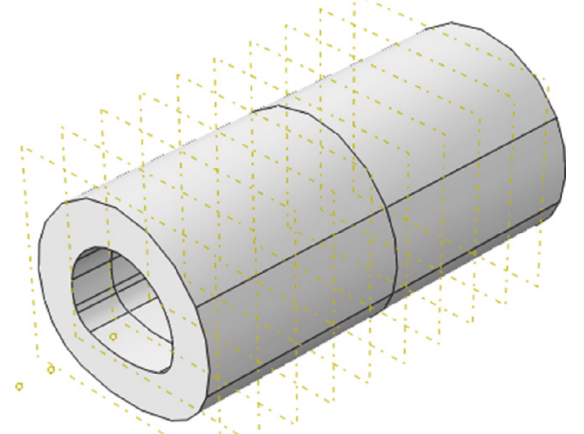

(a) Grouting circle parts

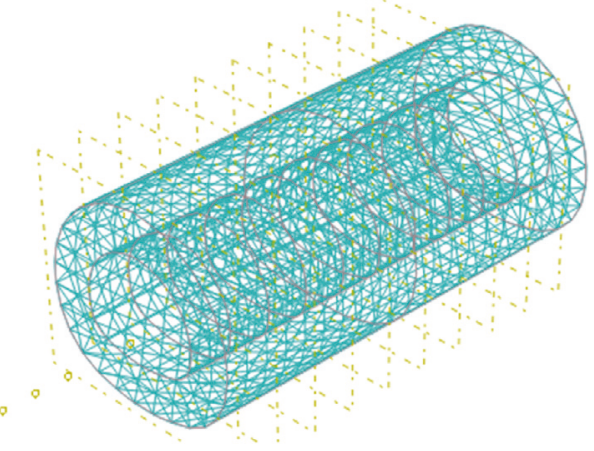

(b) Grid partition of the grouting circle

FIGURE 6: Grouting circle model.
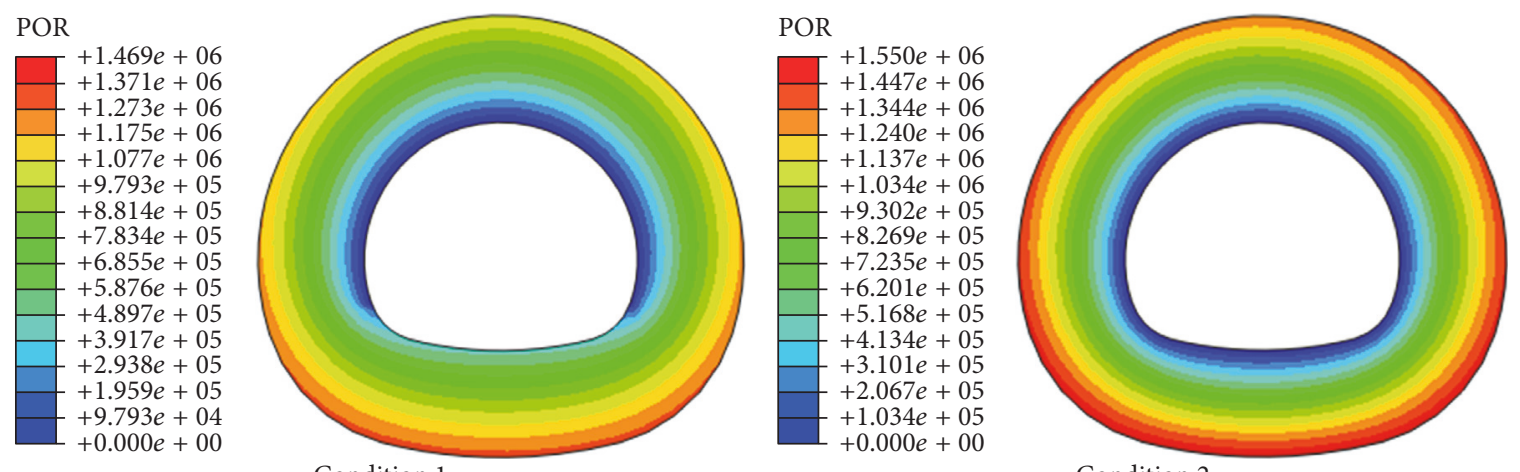

FIGURE 7: The distribution of pore water pressure in the $5 \mathrm{~m}$ range of tunnel excavation.

TABLE 2: Parameters of grouting circle.

\begin{tabular}{lccccc}
\hline $\begin{array}{l}\text { Density } \\
\left(\mathrm{kg} / \mathrm{m}^{3}\right)\end{array}$ & $\begin{array}{c}\text { Modulus of } \\
\text { elasticity } \\
(\mathrm{GPa})\end{array}$ & $\begin{array}{c}\text { Poisson's } \\
\text { ratio } \\
(\mathrm{v})\end{array}$ & $\begin{array}{c}\text { Friction angle } \\
\left({ }^{\circ}\right)\end{array}$ & $\begin{array}{c}\text { Cohesive } \\
\text { force } \\
(\mathrm{MPa})\end{array}$ & $\begin{array}{c}\text { Permeability } \\
\text { coefficient } \\
(\mathrm{m} / \mathrm{h})\end{array}$ \\
\hline 2600 & 6.1 & 0.2 & 41 & 0.8 & $3.06 e-6$ \\
\hline
\end{tabular}

calculation model. The pore pressure was then set and fixed as the permeable boundary condition along the boundary. As a result, the fluid could flow into (or out of) the boundary of the model.

The grouting range is 5 meters from the tunnel excavation contour. The graphics of the grouting circle are shown in Figure 6.

\subsection{Curtain Grouting Model Analysis}

3.2.1. Analysis of Working Conditions. Two kinds of working conditions were analyzed, which were grouting and full section curtain grouting, respectively. Case 1 is the working condition associated with "grouting," and case 2 is that related to "full section curtain grouting." For case 1, the parameters of the grouting circle are the same as that in the surrounding rock. For case 2, the parameters were set up as described in Table 2.
Three key points were selected, as follows: $1 \mathrm{~m}$ outside the wall at the vault, the middle part of the side wall, and the middle arch.

3.2.2. The Analysis of Pore Water Pressure Result. The section of tunnel excavation to $25 \mathrm{~m}$, which is located in the middle of the tunnel section, was studied, and its mechanical and seepage characteristics were analyzed. As shown in Figures 7 and 8 , in the case without grouting and in the $5 \mathrm{~m}$ range of tunnel excavation, the maximum pore pressure appears $5 \mathrm{~m}$ under the middle of the tunnel with a value of $0.145 \mathrm{MPa}$. In the second case, where the grouting circle was 5 meters, the maximum pore pressure appears at the bottom of the lateral grouting circle with a value of $0.155 \mathrm{MPa}$.

3.2.3. The Analysis of Seepage Velocity Results. As shown in Figures 9 and 10, the maximum flow velocity of working condition 1 appears at the foot of the arch with a value of 

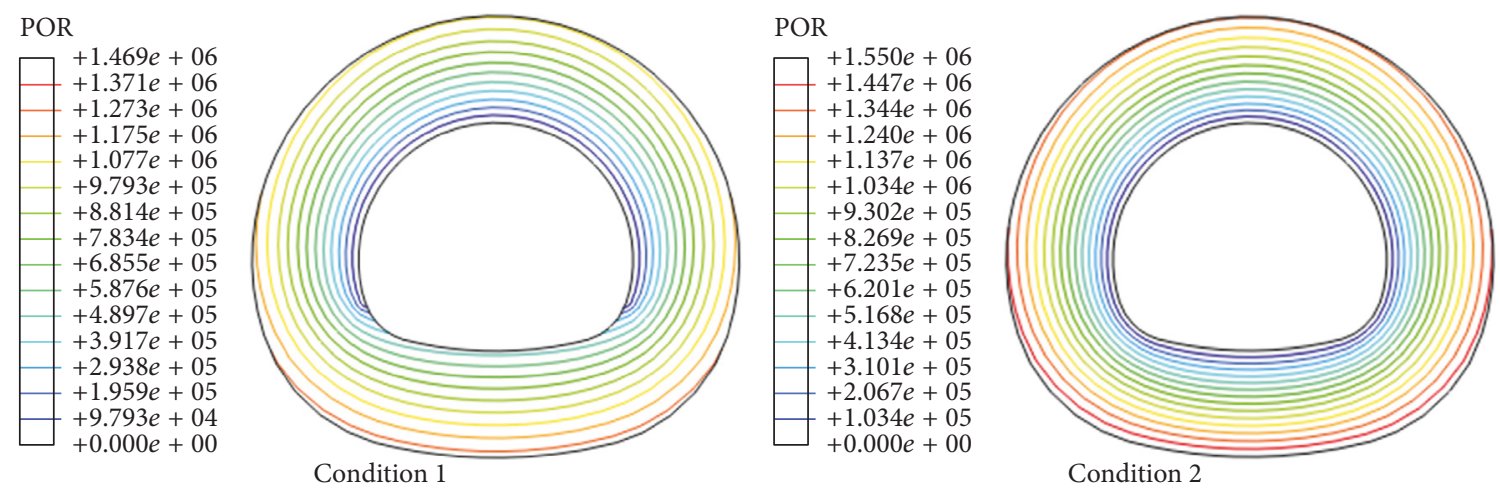

FIGURE 8: Contour map of pore water pressure in the $5 \mathrm{~m}$ range of tunnel excavation.
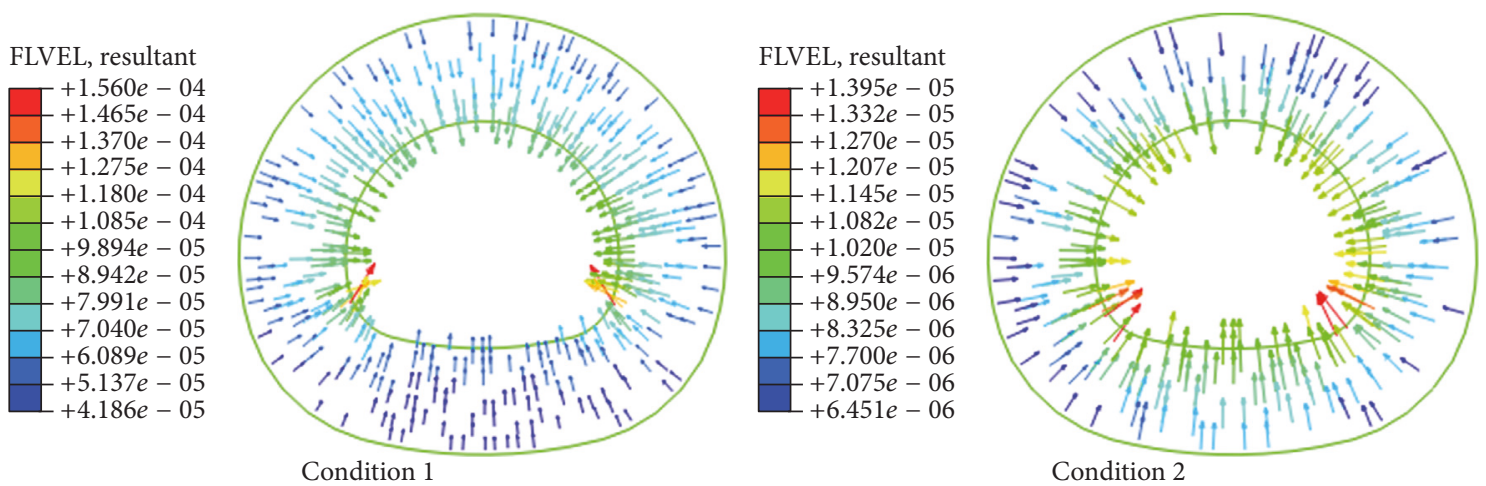

FIgURE 9: Flow velocity vector diagram.
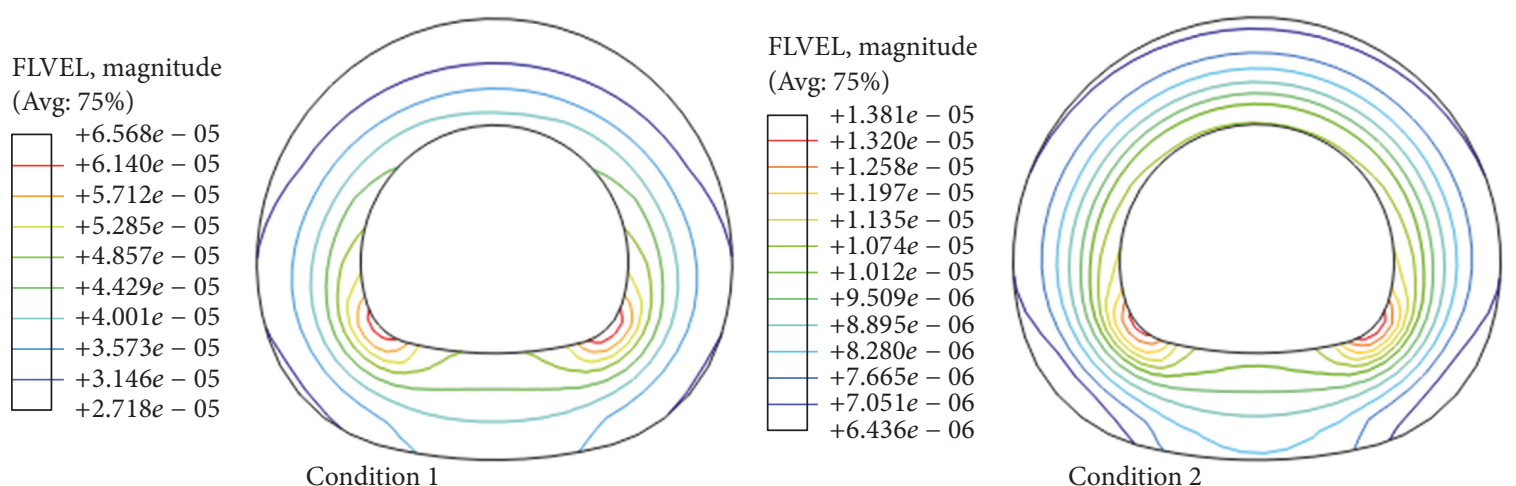

FIGURE 10: Flow velocity contour map.

$1.395 e-5 \mathrm{~m} / \mathrm{s}$. The selected path used to measure the output flow velocity was from the vault to the bottom of the left wall to the bottom of the arch, the flow rate output path diagram is shown in Figure 11, and flow velocity curve is shown in Figure 12.

Our comparison analysis shows that the maximum flow rate of condition 2 is obviously less than that of condition 1 . The difference between the two is an order of magnitude. It shows that grouting can effectively reduce the flow velocity (reducing the flow rate) and block water, which is conducive to the application of the tunnel. Additionally, there is a seepage velocity curves cusp in condition 1 , which indicates that the foot of the arch experiences great changes in the flow velocity where a large number of local seepages may occur and influence lining stability. The change of the flow velocity curve in condition 2 is smooth, which is more advantageous 
TABLE 3: The amplitude of the seepage velocity decreases.

\begin{tabular}{lccccccccccc}
\hline Permeability coefficient ratio & 1 & 2 & 4 & 6 & 8 & 10 & 12 & 14 & 16 & 18 & 20 \\
\hline Seepage velocity $(e-5)$ & 14.8 & 13.7 & 11.3 & 9.49 & 8.26 & 7.31 & 6.55 & 5.94 & 5.45 & 5.02 & 4.65 \\
Decrease amplitude (\%) & & 9.27 & 24.73 & 36.29 & 44.62 & 50.94 & 56.05 & 60.15 & 63.51 & 66.40 & 68.82 \\
\hline
\end{tabular}

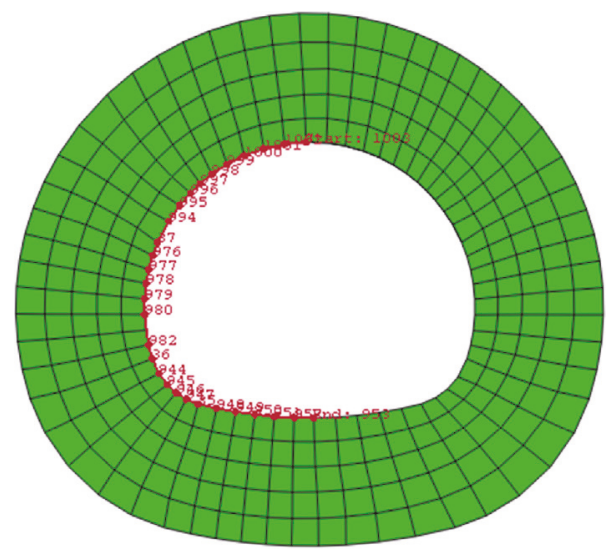

FIGURE 11: Flow rate output path diagram.

to the stability of the lining structure. Accordingly, based on the results of condition 2 , the whole section curtain grouting method is adopted to optimize the parameters.

\section{Optimization Analysis of Curtain Grouting Parameters}

The numerical simulation of the tunnel grouting effect in the field is carried out according to the geological conditions of the field. The grouting circle was mainly studied through numerical analysis. The thickness of the grouting circle reflects the variation found in the permeability coefficient and the tunnel seepage water size. Thus through numerical analysis, one can obtain the more reasonably sized grouting circle using the permeation coefficient of the grouting parameters, in order to optimize construction.

4.1. Optimization Analysis on the Permeability Coefficient of the Grouting Circle. We performed an analysis of the thickness of the grouting ring under pore water pressure, which was located at $5 \mathrm{~m}$, as well as the change of the permeability coefficient of the grouting circle. In this equation, $k_{r}$ is permeability coefficient of the surrounding rock, $k_{g}$ is the permeability coefficient of the grouting circle, and $k_{r} / k_{g}$, respectively, represent $2,4,6,8,10,12,14,16,18$, or 20 . The calculated values of the pore water pressure are shown in Figure 13. The variation of the pore water pressure within the permeability coefficient is shown in Figure 14.

When the seepage velocity was reduced, the maximum decreased amplitude occurred on the roof of the tunnel. We selected the flow velocity as the research object and calculated the decreased amplitude of the seepage velocity when the permeability coefficient changed. Thus, the most effective permeability coefficient was obtained:

$$
\eta_{n}=\frac{v_{1}-v_{n}}{v_{1}} \times 100 \%
$$

where $\eta_{n}$ is the decreased amplitude of the seepage velocity when the ratio of the permeability coefficient is $n$; $v_{n}$ is the seepage velocity when the ratio of the permeability coefficient is $n$; and $v_{1}$ is the seepage velocity when the ratio of the permeability coefficient is 1 , which is to say, the initial seepage velocity; the amplitude of the seepage velocity decreases is shown in Table 3.

Through data analysis, we understood that when the ratio of the permeability coefficient increases, the amplitude of the seepage velocity decreases. When the growth rate of the two groups was increased to 4, the amplitude of the increase slowed down, which indicates that the effect of seepage velocity is nonconspicuous.

4.2. Optimization of Thickness of Grouting Circle. In this study, the permeability coefficient of the surrounding rock and grouting circle were controlled, the range of the grouting circle was adjusted, and the thickness of the grouting ring was selected for $2 \mathrm{~m}, 4 \mathrm{~m}, 6 \mathrm{~m}, 8 \mathrm{~m}, 10 \mathrm{~m}$, and $12 \mathrm{~m}$. The relationship curves of the flow velocity and the thickness of the grouting ring are shown in Figure 15.

When the thickness of the grouting ring increases, the seepage velocity decreases, and curves occur in the form of concave functions. The seepage velocity in the bottom is significantly reduced when the grouting circle thickness is $4 \mathrm{~m}$, which suggests that the flow velocity of the grouting circle in the bottom and in the arch is significant, whereas the influence of the velocity of the vault is relatively small.

4.3. The Influence of Surrounding Rock Permeability Coefficient. We determined the influence of changes in the surrounding rock by calculating the permeability coefficient in the seepage velocity after the tunnel was excavated and compared with data with a grouting circle that had a thickness of $5 \mathrm{~m}$ versus nongrouting. According to the field measurements of the permeability coefficient and the range of water pressure variation obtained by field monitoring, we selected three groups, which were comprised of $3.05 e-5,1.2 e-6$, and $2.55 e-7$. The permeability coefficient of the grouting circle is smaller than that of the surrounding rock, with values of $3.05 e-6,1.2 e-7$, and $2.55 e-7$.

When the grouting ring is $5 \mathrm{~m}$ thick, the penetration speed of tunnel periphery is shown in Table 4 .

When using nongrouting, the penetration speed of tunnel periphery is shown in Table 5. . 


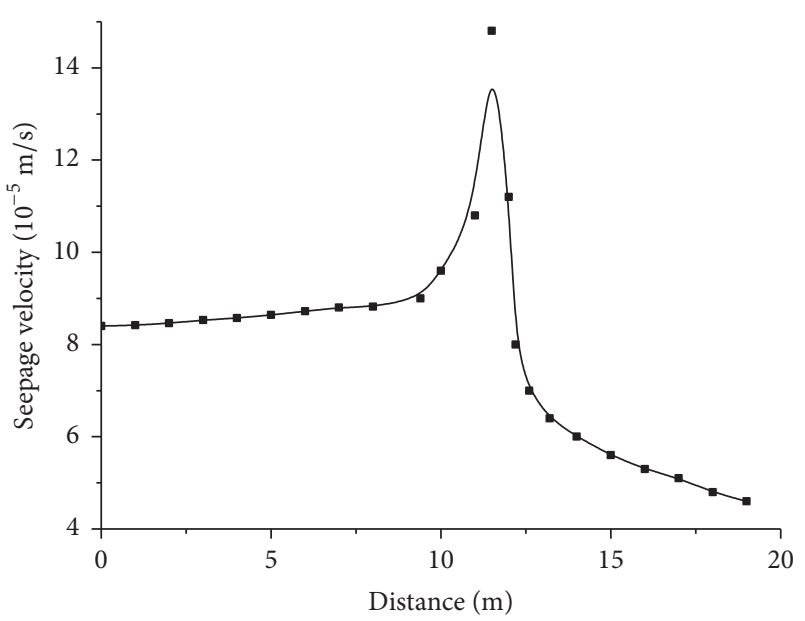

(a) Flow velocity curve of condition 1

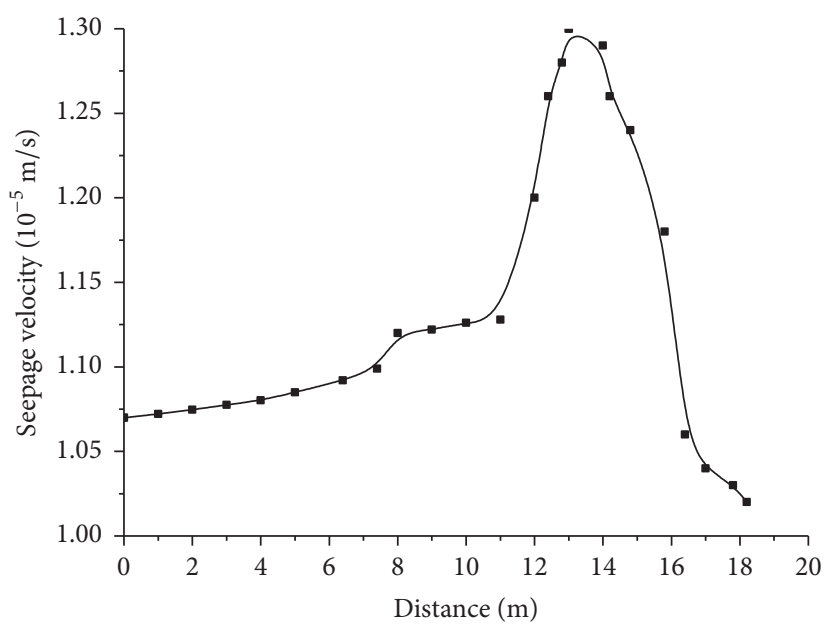

(b) Flow velocity curve of condition 2

FIGURE 12: Flow velocity curve.

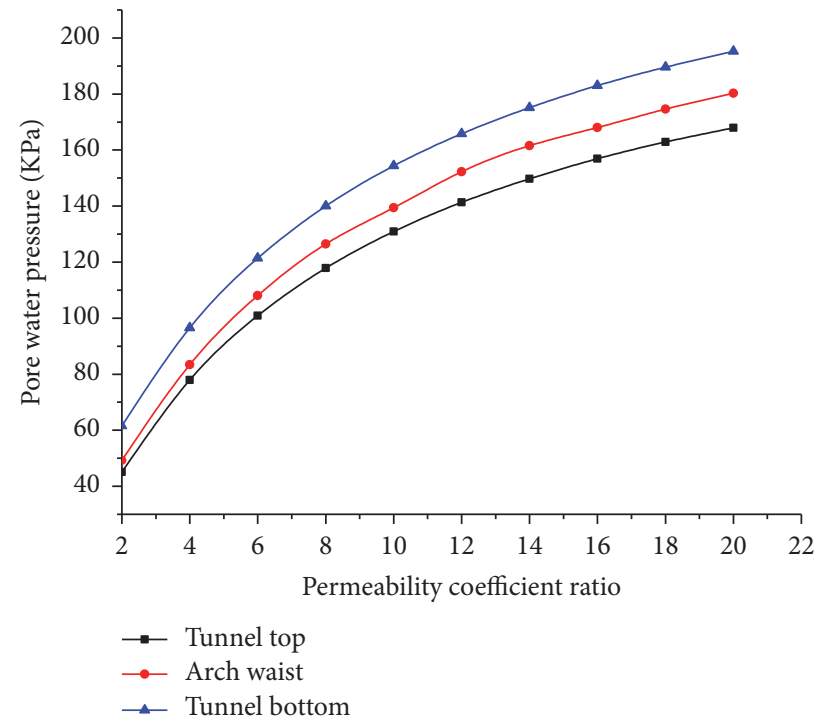

FIGURE 13: Relationship of pore water pressure and permeability coefficient of grouting circle.

TABLE 4: The relationship between infiltration rate and the permeability coefficient of surrounding rock when grouting ring is $5 \mathrm{~m}$.

\begin{tabular}{lccc}
\hline$K(\mathrm{~m} / \mathrm{s})$ & The top $(\mathrm{m} / \mathrm{s})$ & The $\operatorname{arch}(\mathrm{m} / \mathrm{s})$ & The bottom $(\mathrm{m} / \mathrm{s})$ \\
\hline $2.55 e-07$ & $1.22 E-06$ & $9.22 E-07$ & $9.54 E-07$ \\
$1.20 e-06$ & $5.72 E-06$ & $4.34 E-06$ & $4.48 E-06$ \\
$3.05 e-05$ & $1.46 E-04$ & $1.11 E-04$ & $1.14 E-04$ \\
\hline
\end{tabular}

Through analyzing the data and comparing the two alternative conditions, including using a larger grouting circle and nongrouting, we can see that the grouting circle reduces the flow velocity, thus effectively controlling the seepage flow. Furthermore, using numerical simulation analysis, we

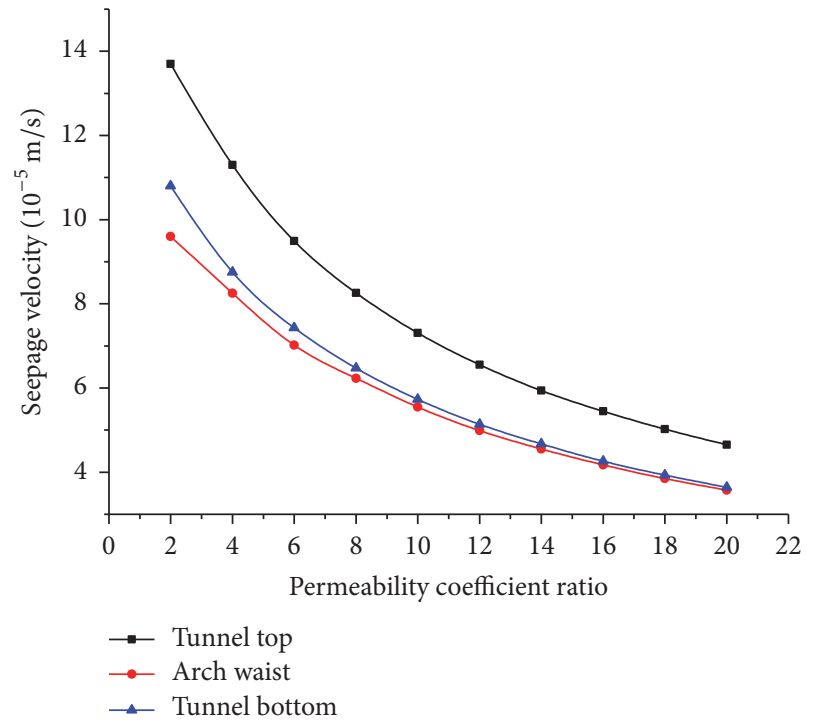

FIGURE 14: Relationship of seepage velocity and permeability coefficient of grouting circle.

TABLE 5: The relationship between infiltration rate and the permeability coefficient of surrounding rock when nongrouting.

\begin{tabular}{lccc}
\hline$K(\mathrm{~m} / \mathrm{s})$ & The top $(\mathrm{m} / \mathrm{s})$ & The arch $(\mathrm{m} / \mathrm{s})$ & The bottom $(\mathrm{m} / \mathrm{s})$ \\
\hline $2.55 E-07$ & $1.71 E-06$ & $1.24 E-06$ & $1.28 E-06$ \\
$1.20 E-06$ & $8.06 E-06$ & $5.84 E-06$ & $6.00 E-06$ \\
$3.05 E-05$ & $2.06 E-04$ & $1.58 E-04$ & $1.53 E-04$ \\
\hline
\end{tabular}

understand that although the grouting circle reduces the flow velocity, because the pore water pressure in the grouting circle has increased, the grouting circle must bear more pressure. 
Through a comprehensive summary of the field grouting data and theoretical analysis, the following grouting optimization is made.

The results of numerical simulation indicate that the most effective grouting circle thickness for resisting water pressure is $4 \mathrm{~m}$. However, the standard designed thickness of the grouting circle is $5 \mathrm{~m}$, so we recommend reducing the outer ring to $4 \mathrm{~m}$ for the tunnel contour. The final grouting pressure data that is provided in the design is $2.0 \mathrm{MPa}$, but the actual calculation of the maximum pore pressure is 1.8 $\mathrm{MPa}$. When the grouting pressure is too large, the original intact rock mass may fracture, which can result in karst or karst weak rock damage, thus causing them to connect, which significantly increased the grouting volume. The final pressure is thus $1.8 \mathrm{MPa}$ by amendment. In addition, the pressure gauge on the grouting machine is too large (16 Mpa), and it is not accurate enough; thus, we propose changing the range to $3 \mathrm{MPa}$ and the accuracy to $0.1 \mathrm{MPa}$.

\section{Grouting Program Implementation and Effect Analysis}

5.1. Grouting Material and Parameter Selection. Grouting process is injecting cementitious material into the rock layer by certain pressure, so that it can be diffused and consolidated in the fissures of rock formations. Finally, the stone body is formed and the water flow is cut off. Therefore, according to the water plugging requirements and formation conditions of the tunnel, the mobility of the grouting material, easy to inject cracks, environmental protection, economic performance, and so forth, combined with the above numerical analysis and optimization recommendations, cement grouting was selected as the grouting material. When there is a small amount of water and mud in the dissolved cavity, one may change the grouting material to cement and water and use a glass slurry, or (if necessary) stop construction. In order to select the grouting parameters, we suggest the following recommendations: using ordinary Portland cement, number 32.5; Baume of sodium silicate $\mathrm{Be}=40$; water-cement ratio of the cement Chey $=0.8 \sim 1: 1$; ratio of cement Chey and sodium silicate 1.25; radius of a single grouting hole effective diffusion $1.5 \mathrm{~m}$; final hole spacing $2.0 \mathrm{~m}$; the grouting range is $4 \mathrm{~m}$ outside of the tunnel excavation contour; final grouting pressure 1.5 2 MPa; slurry wall thickness $2.5 \mathrm{~m}$; the length of the longitudinal reinforcement $30 \mathrm{~m}$; curtain thickness $4 \mathrm{~m}$ outside of the tunnel excavation contour and working face; and number of grouting holes 240 .

5.2. Grouting Pipe Connections. One should connect grouting pipe according to Figure 15. Applying pressurized water could help determine the pipe's tightness, whereas rinsing the rock fractures and expanding slurry path increase the density of the slurry's fill. In order to check the quality of one's grouting equipment, one can assume that the water pressure in the test is generally 1.2 times the suggested design grouting pressure. In the borehole of the general pressure, a grouting stopper with human or mechanical assistance can be fed into the hole in the case as far as possible. At high hydrostatic pressure, it is difficult to use a common stopper to plug the hole; therefore,

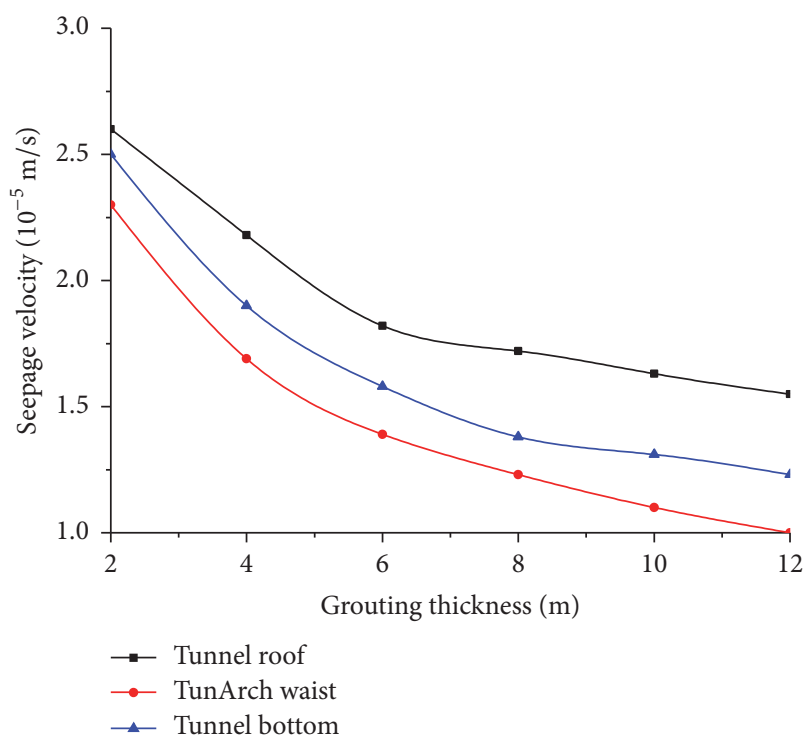

FIGURE 15: Flow velocity curve.

it is necessary to install a stopper valve in the orifice tube; the grouting pipe connections are shown in Figure 16.

5.3. Curtain Grouting Work Process. By drilling the grouting hole in the face of the worksite and then injecting the cement and water in a glass double slurry and cement grouting into the hole, the water will be squeezed out of the rock fractures and from a small surrounding area. By using grout fill to bond the rock fractures, they become integrated and a sealing curtain is formed. Those working with grout should follow the principle of doing grouting while releasing the dissolved cavity pressure by adjusting the valve. It is appropriate to have a relief hole in the vicinity of the upper half of the center tunnel. One should grout the outer ring first, followed by the inner ring, and the upper section first, followed by the lower section, and use a forward-moving grouting technique; the curtain grouting plan is shown in Figure 17.

5.4. Grouting Effect Evaluation. The grouting process was studied according to information regarding the grouting pressure, grouting volume, and time indicated in the field research. The grouting hole distribution is shown in Figure 18. The first to fifth lap grouting holes in the tunnel were selected for study. Moving from the outside to the inside, one should divide the grouting holes in the nine laps and select five laps from the outermost grouting hole for further research. The actual injection pressure can be seen in Figure 19.

From Figures 19 and 20 we know the following:

(1) When grouting starts, the grouting pressure remains relatively stable at around $1.6 \sim 1.7 \mathrm{MPa}$. The rate of pressure tends to increase gradually; when the pressure reaches 1.9 2.0 $\mathrm{MPa}$, the grouting pressure becomes constant.

(2) At the beginning, the grouting flow rate of each hole should be about $4 \sim 5 \mathrm{~m}^{3} / \mathrm{h}$. 


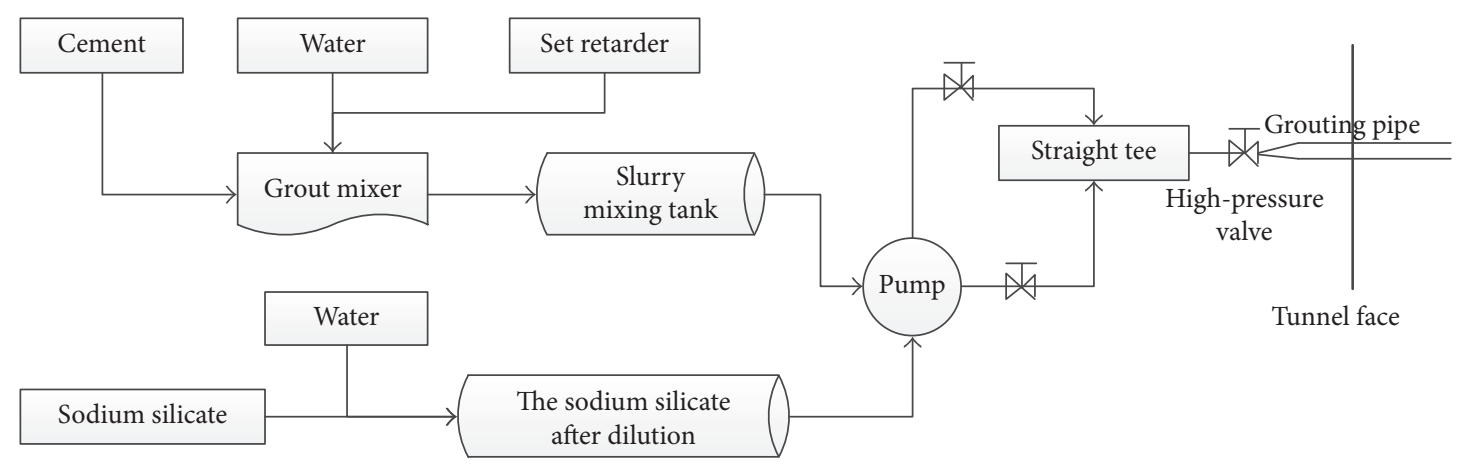

FIGURE 16: Grouting pipe connections.

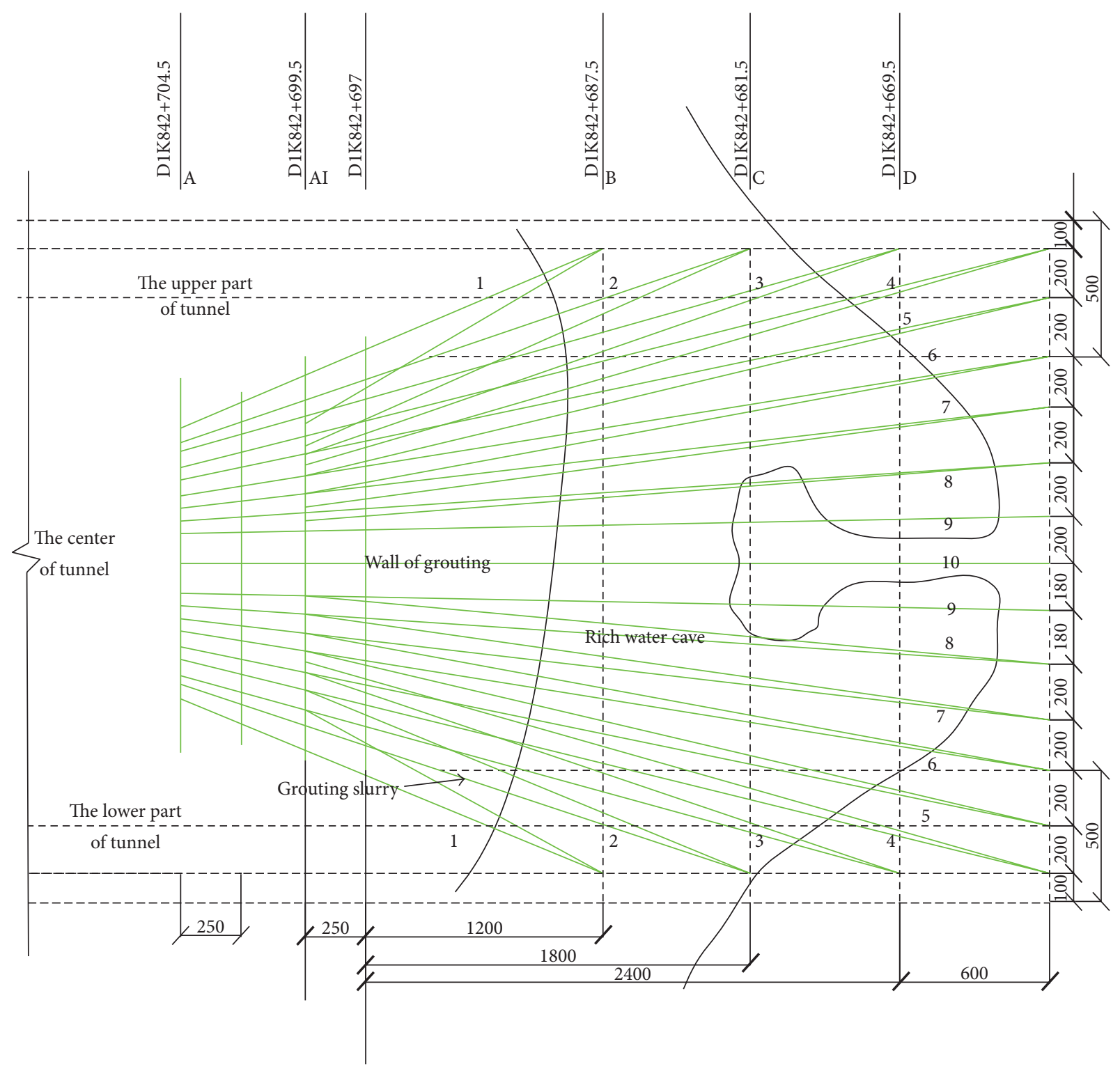

FIGURE 17: Curtain grouting plan. 


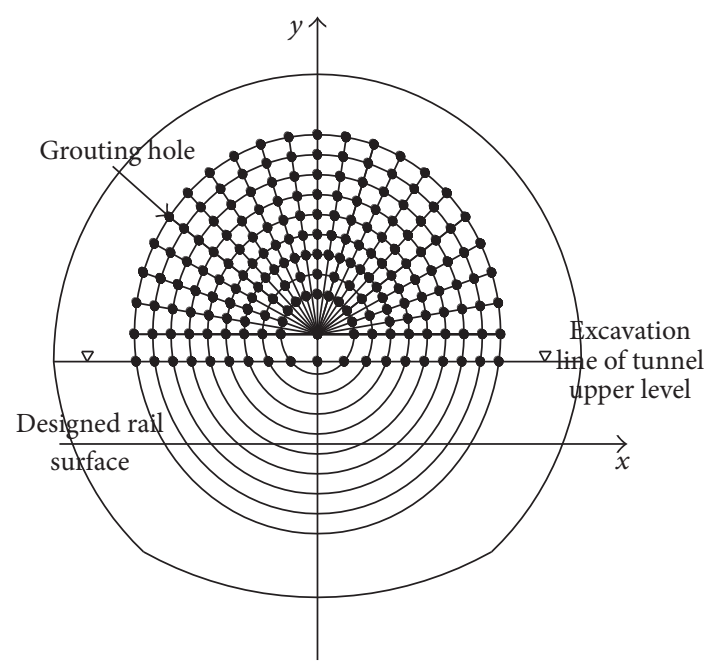

FIGURE 18: The layout of grouting hole.

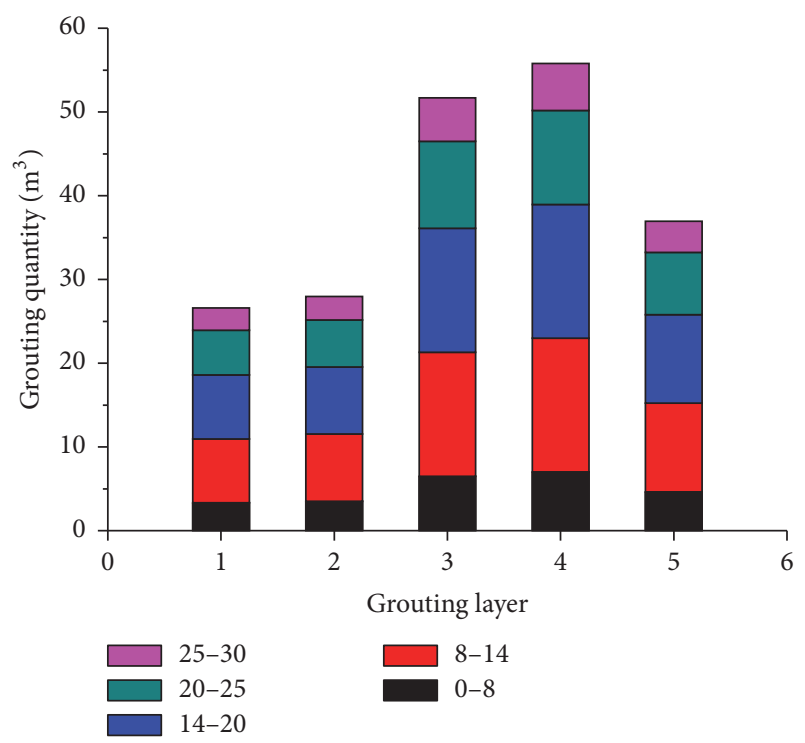

FIGURE 19: Section grouting quantity.

Within $80 \mathrm{~min}$, the grouting rate changed little. The grouting speed gradually reduces in a linear trend, and when it reaches 120 140 min, the change in the grouting speed is small and tends to remain stable.

(3) The grouting pressure and speed demonstrated a shift in the relationship, which means that when the grouting pressure increased, the speed decreased.

(4) The area between $0 \sim 8 \mathrm{~m}$ and $25 \sim 30 \mathrm{~m}$ of the grouting section is small and only about $30 \%$ of the total. Most of the grouting holes are concentrated in the 8 25 m segment, because of the dissolved cavity in $8 \sim 25 \mathrm{~m}$ bulky void. When compared with the outermost layer and the second outer layer of the tunnel face, the grouting amount of third and fourth layers is significantly larger, because of the fact that

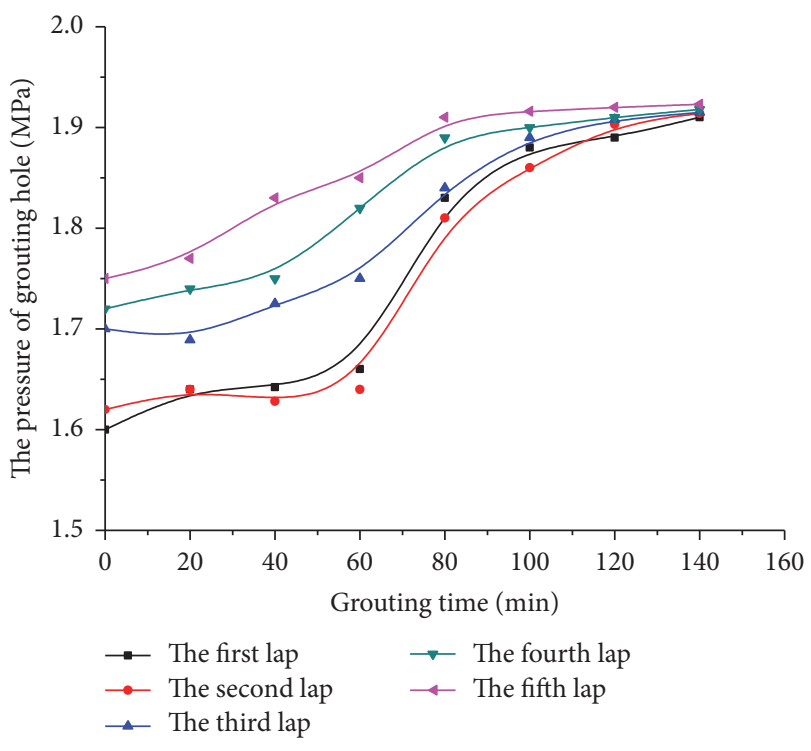

FIGURE 20: Grouting pressure of grouting hole.

the dissolved cavity was mainly located in the third and fourth layers.

There is a $7 \mathrm{~m}$ distance between the grouting occluding wall and dissolved cavity. At this distance, there were relatively fewer fractures and pores and the grouting did not completely reach the cavern, so the volume of the starting section $(0 \sim 7 \mathrm{~m})$ was not large. When the grouting hole was deeper and reached the cavern, the amount began to significantly increase. Moreover, when the grouting hole broke through the dissolved cavity at the far end to reach the wall, the amount of rock fracture reduced, so the amount grouting slowly reduced, as well.

The grouting pressure fluctuated a little but generally remained in the range of $1.7 \mathrm{MPa} 1.9 \mathrm{MPa}$. The grouting pressure in each circle changed a little. The maximum pressure change was $0.22 \mathrm{MPa}$, which occurred between the eighth and ninth holes in the first lap. The grouting pressure finally tended to stabilize around $1.9 \mathrm{MPa}$.

We selected sections at DK842+695, DK842+685, and DK842+675 as the test sections to monitor and analyze the settlement data. When excavating, one should choose a section (DK842+720) before the grouting interval as the reference section, as Figure 21 shows.

From Figure 21, the following can be known:

(1) The overall trend of the settlement of the four sections tended to first increase, then stabilize, and finally reach a relatively stable state, wherein the settlement value does not increase.

(2) The DK842+720 section has a solid rock wall that did not need grouting. The wall's final settlement was at $2.6 \mathrm{~mm}$, which was obviously less than the grouting monitor section (DK842+695, DK842+685, and DK842+675).

(3) The settlement curve of grouting section increases linearly in the beginning and the slopes of the linear 


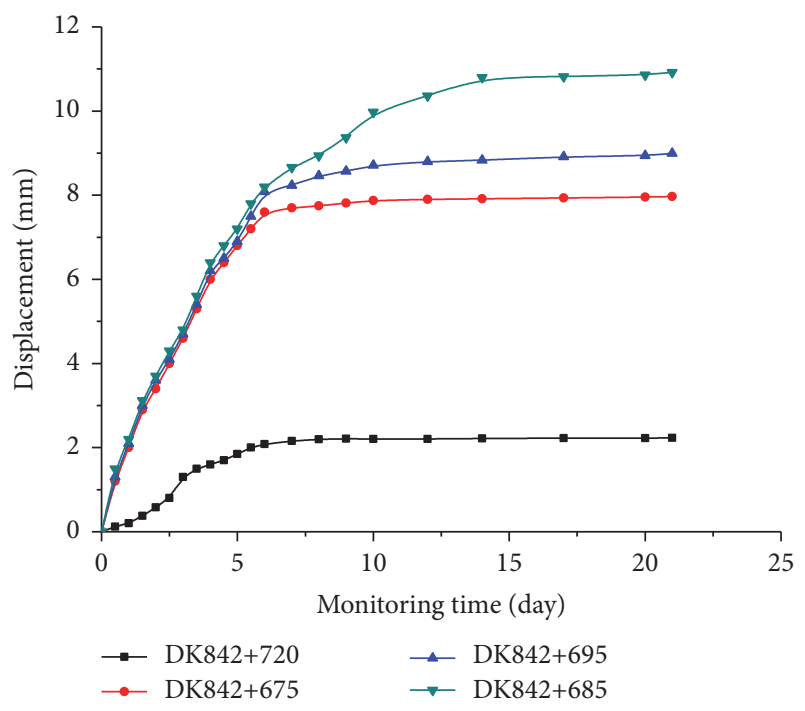

FIGURE 21: The subsidence change of tunnel surrounding rock.

increase segment are basically the same in the three curves. Seven days after tunneling through the observation section, the tunnel settlement shows an apparent convergence and curve's curvature stabilized.

\section{Conclusion}

We have gathered the following conclusions through optimizing the curtain grouting parameters and evaluating the grouting effects in the Dou-mo tunnel work zone.

(1) In this paper, the optimization analysis of grouting parameters and the evaluation of grouting performance have greatly compensated for the uncertainty of grouting parameters determined by engineering experience, so the grouting effect can be effectively controlled.

(2) For a karst-filled dissolved cavity, curtain grouting technology should be used under the situation when the water pressure is not adequate, and the water pressure is distributed within a limited range of the tunnel line.

(3) When the grouting circle is in a $4 \mathrm{~m}$ range of the tunnel contours, the grout plugging effect is most significant. Reducing the grouting range to within $4 \mathrm{~m}$ is recommended and it could reduce the cost of the project materials.

(4) When the grouting volume of a hole in the same lap shows wavy variation, it may be appropriate to reduce the number of grouting holes in same lap and increase the distance between adjacent grouting holes with rings, thereby reducing the number of grout drilling, which will accelerate the grouting progress.

(5) If the settlement of the curtain in a grouting section is still higher than that of a normal section, then deformation in the control tunnel becomes an important concern. Five surrounding rock support methods were recommended, which must be used as quickly as possible to close the loop, in addition to adopting a three-step, plus temporary, lateral bracing method.

\section{Conflicts of Interest}

The authors declare that they have no conflicts of interest.

\section{Acknowledgments}

This work was supported by the National Natural Science Foundation of China (no. 41372351, no. 41672339).

\section{References}

[1] S. Dalgiç, "Tunneling in squeezing rock, the Bolu tunnel, anatolian motorway, Turkey," Engineering Geology, vol. 67, no. 1-2, pp. 73-96, 2002.

[2] P. Egger, "Design and construction aspects of deep Tunnels (with particular emphasis on strain softening rocks)," Tunnelling and Underground Space Technology, vol. 15, no. 4, pp. 403-408, 2000.

[3] Q. Zhang, P. Li, G. Wang et al., "Parameters Optimization of Curtain Grouting Reinforcement Cycle in Yonglian Tunnel and Its Application," Mathematical Problems in Engineering, vol. 2015, Article ID 615736, 2015.

[4] R. Jian, "Grouting technology for construction of mountain tunnel in high-pressure water rich fault fracture zone," Journal of railway engineering society, vol. 58, no. 5, pp. 58-62, 2010.

[5] K. G. Raven and J. E. Gale, "Water flow in a natural rock fracture as a function of stress and sample size," International Journal of Rock Mechanics and Mining Sciences and, vol. 22, no. 4, pp. 251261, 1985.

[6] C. K. Shen, S. Bang, K. M. Romstad, L. Kulchin, and J. S. DeNatale, "Closure to "," Journal of Geotechnical Engineering, vol. 109, no. 3, pp. 490-490, 1983.

[7] D.-J. Tseng, B.-R. Tsai, and L.-C. Chang, "A case study on ground treatment for a rock tunnel with high groundwater ingression in Taiwan," Tunnelling and Underground Space Technology, vol. 16, no. 3, pp. 175-183, 2001.

[8] S. C. Nichols and D. J. Goodings, "Physical model testing of compaction grouting in cohesionless soil," Journal of Geotechnical and Geoenvironmental Engineering, vol. 126, no. 9, pp. 848$852,2000$.

[9] J. H. Shin, T. I. Addenbrooke, and D. M. Potts, "A numerical study of the effect of groundwater movement on long-term tunnel behaviour," Geotechnique, vol. 52, no. 6, pp. 391-403, 2002.

[10] M. Eriksson, M. Friedrich, and C. Vorschulze, "Variations in the rheology and penetrability of cement-based grouts-An experimental study," Cement and Concrete Research, vol. 34, no. 7, pp. 1111-1119, 2004.

[11] P. F. Li, D. Zhang, Y. Zhao, and C. Zhang, "Study of distribution law of water pressure acting on composite lining and reasonable parameters of grouting circle for subsea tunnel," Chinese Journal of Rock Mechanics and Engineering, vol. 31, no. 2, pp. 280-288, 2012.

[12] J. Mirzaa, M. S. Mirzab, V. Roya, and K. Saleh, "Basic rheological and mechanical properties of high-volume fly ash grouts," Construction and Building Materials, vol. 16, pp. 353-363, 2002. 
[13] R. Gothäll and H. Stille, "Fracture dilation during grouting," Tunnelling and Underground Space Technology, vol. 24, no. 2, pp. 126-135, 2009.

[14] M. A. Meguid and R. K. Rowe, "Stability of D-shaped tunnels in a Mohr-Coulomb material under anisotropic stress conditions," Canadian Geotechnical Journal, vol. 43, no. 3, pp. 273-281, 2006.

[15] C. L. Wang, Study on Risk Identification and Warning of Karst Water Bursting Disaster of Railway Tunnel, Beijing Jiaotong University, Beijing, China, 2015.

[16] S. C. Xing, The Construction Method Research of Karst Tunnel Full of Water, Beijing Jiaotong University, Beijing, China, 2014. 

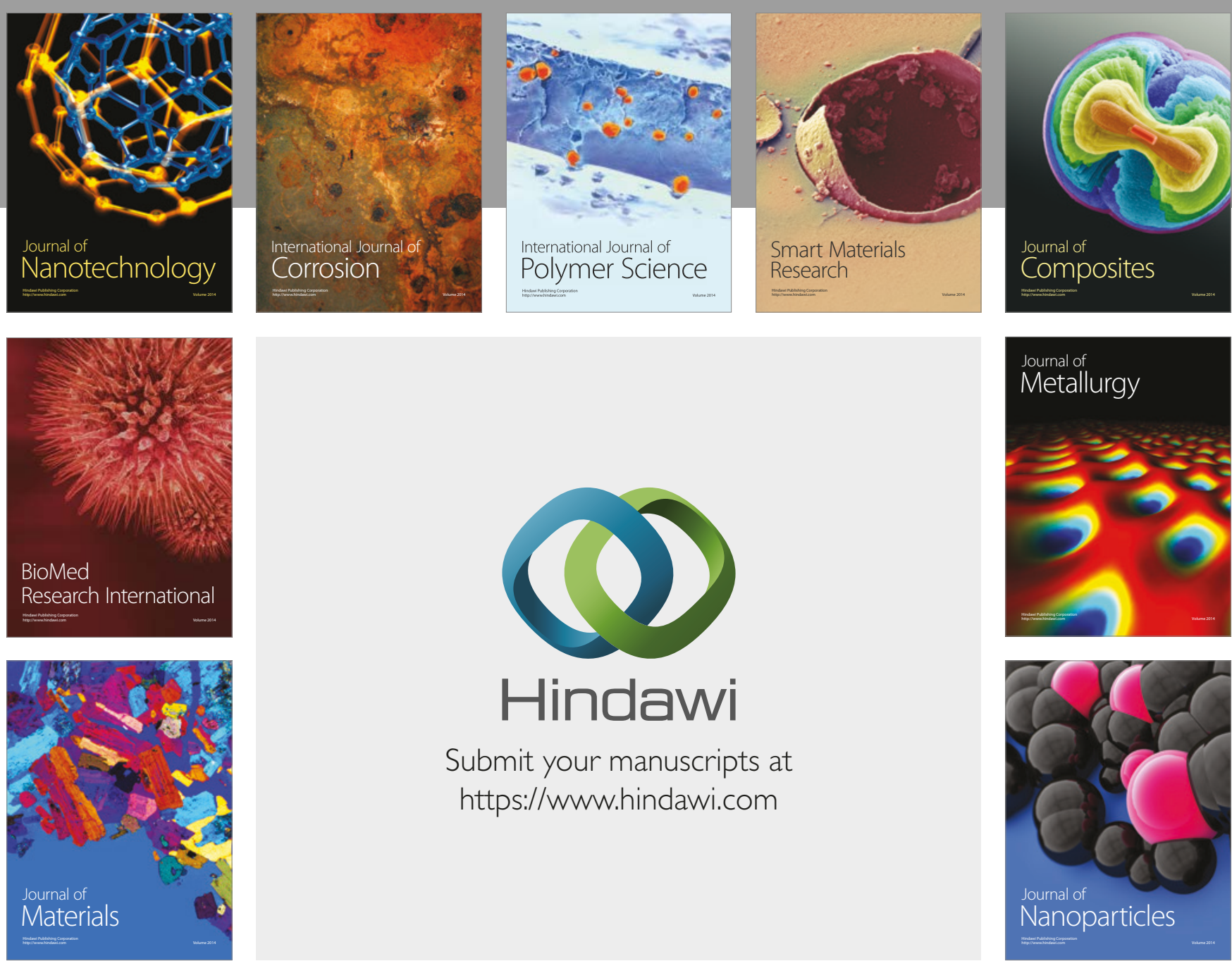

\section{Hindawi}

Submit your manuscripts at

https://www.hindawi.com
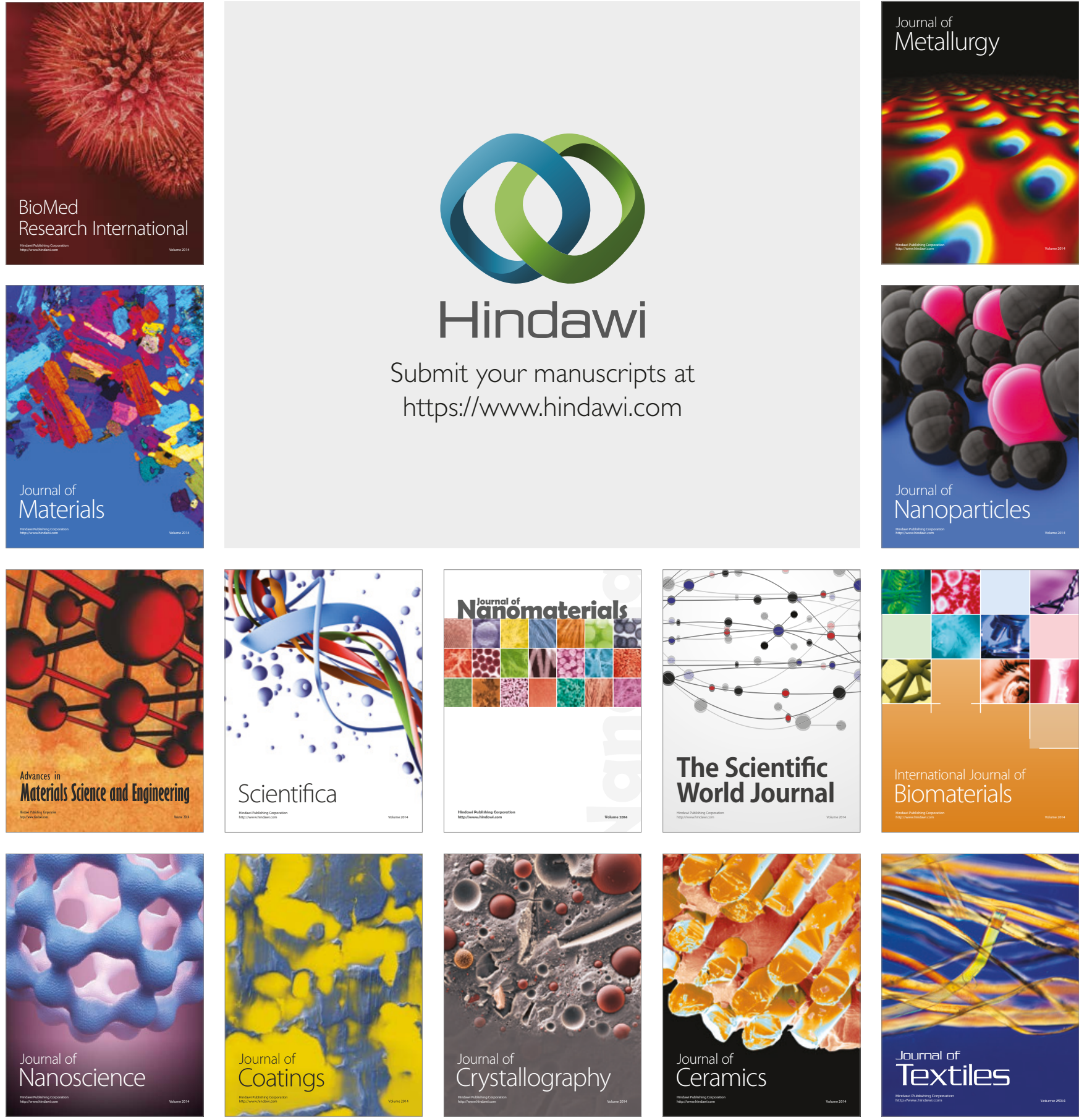

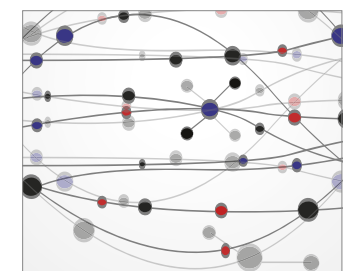

The Scientific World Journal
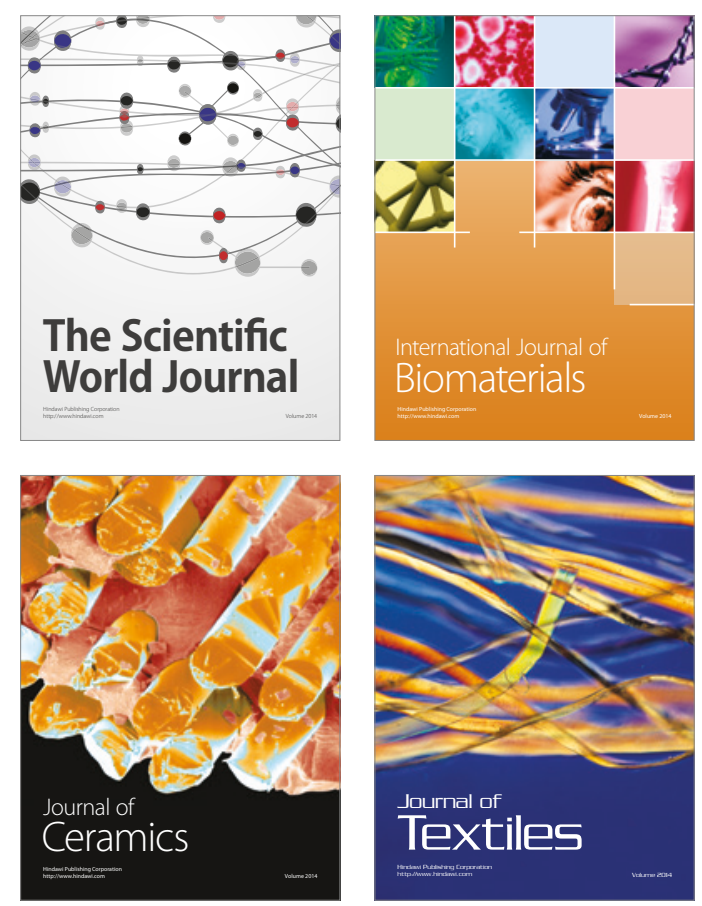